\title{
The results of pre-sowing conifer seeds treatment by growth stimulators
}

\author{
Aigul Mukhametshina ${ }^{1, *}$, Renat Gafiyatov ${ }^{1}$, Lyudmila Pukhacheva ${ }^{1}$, Shamil Shaikhraziev ${ }^{1}$, and Almaz Akhmetov ${ }^{2}$ \\ ${ }^{1}$ Kazan state agricultural university, 420015 Kazan, Russia \\ ${ }^{2} \mathrm{HCU}$ Zelenodolsk experimental forestry, 422530 Zelenodolsk district, Republic of Tatarstan, Russia
}

\begin{abstract}
The article studies the influence of different fertilizing products on vigor and germinating ability of Scots pine and common spruce seeds. The research involved the following products: Humate+7, Potassium humate "Sufler", Biohumus, Agrostimul VE, Emistim-R, Gibberellin, Etamon. The soaking of seeds in products leads to an increase in vigor, on average, between 31 and $37.0 \%$ for Scots pine and between 5 and $13.0 \%$ for common spruce. The germinating ability of Scots pine and common spruce seeds increases, on average, by 16.0 and $17.0 \%$ correspondingly. Among all the products the least effective was "Etamon". In its case, the germinating ability of seeds in laboratory conditions was $53.0 \%$ which is $10.0 \%$ lower than in control. The treatment by stimulators significantly influenced the development of a root system. The intensive root growth happens in the cases of "Gibberellin" and "Humate+7" -4.4 and $5 \mathrm{~cm}$ corresponding to the variants of the experiment. The pre-sowing treatment positively increases the length of germs. In this case, the best results were achieved with "Gibberellin" and "Biohumus" products that gave the increase of 1.7 and $1.5 \mathrm{~cm}$ respectively.
\end{abstract}

\section{Introduction}

The preparation of forest plant seeds for sowing is aimed at overcoming deep or induced dormancy, stimulating mass seed germination and increasing their field germination [1]. Knowing the reasons for dormancy allows for creating and using different techniques of overcoming it by special pre-sowing treatment.

The most common ways to prepare conifer seeds for sowing used in the Republic of Tatarstan and other regions of Russia are storage in snow layers and, sometimes, further pre-sowing treatment by growth activators (soaking).

The pre-sowing treatment is based on a special mechanism: when microelements in growth activators effect on seeds, the plasm of corcule cells is deeply changed which determines the further growth and development of plants. Microelements speed up the germination by $2-4$ days, increase the field germination of seeds, their vigor, and stability to unfavorable conditions of the environment and diseases. They also increase the growth and development of plants. The use of microelements increases the liveability of young plants by 20-40\%, especially in bad weather years [2-4].

The use of stimulators for growth and development of plants is one of the most important directions to increase the efficiency of young plant growing. At present, the influence of a big number of chemical compounds on different conifer seeds was studied in our country. The most common stimulators used in practice are cobaltous nitrate, copper sulfate, iron, magnesium, manganese, zinc, boric acid, molybdenum ammonium, gibberellin, heteroauxin, petroleum-based growth substance, etc [5-8]. The pre-sowing treatment of seeds by Verva and Verva-el products at a concentration of 0.1 liter $0.25 \mathrm{mg} / \mathrm{kg}$ by means of soaking for 6 hours has led to prolonged influence on the growth indicators in case of pine plantlets. The height of 1-year plantlets was bigger than control by $40-84 \%$, while the height of 2-year plantlets was bigger by $29-47 \%$. The diameter of the trunk of 1-year plantlets was bigger by $10-43 \%$ while in the case of 2-year plantlets it was bigger by 11-40\% [9].

When doing the pre-sowing treatment, it is necessary to take into account that effects may be achieved when there is severe lack of used microelements in soil and they are the constraint for young plant growth [10].

The article contains the information about modern ideas about biostimulators used to adjust the growth of plants, reduce the negative effects of abiotic and biotic stress factors and increase the fertility of agricultural plants $[11,12]$.

However, the majority of modern products are tested and used for growing crops. That's why the pre-sowing treatment of conifer seeds is an important research direction in the forestry sector.

\section{Objects and methods of research}

The laboratory tests of conifer seed sprouting were carried out between 2018 and 2019. The following

* Corresponding author: aigulsafina@yandex.ru 
products were used to test the efficiency of soaking seeds of Scots pine and common spruce: Humate+7, Potassium humate "Sufler", Biohumus, Agrostimul VE, Emistim-R, Gibberellin, Etamon.

Agrostimul VE (water emulsion) is a highly efficient biological growth and development stimulator for plants. It contains $50 \mathrm{~g}$ of dihydroquercetin per liter. It starts to affect after 15-20 minutes after treatment. As a result of treatment, seeds become more immune to diseases and unfavorable environmental factors. It also increases fertility and resistance to diseases.

Emistim- $\mathrm{R}$ is a growth stimulator that increases the field germination rate, immunity to diseases and unfavorable environmental factors.

The contents of Humate+7 iodine: the mixture of potassium and/or sodium salts of humic acids $-76 \%$; potassium - 5\%; copper - $0.2 \%$; zinc - $0.2 \%$; manganese $-0.17 \%$; iodine $-0.005 \%$; molybdenum $0.018 \%$; cobalt $-0.02 \%$; iron $-0.4 \%$; borium $-0.2 \%$.

The contents of Potassium humate "Sufler": potassium - 0.2-0.3\%; organic matter - not less than $1.35 \%$; humate in organic matter - not less than $40 \%$.

The contents of Biohumus: humic acids - not less than $3 \mathrm{~g} / \mathrm{l}$, microelements in a dissolved state, humates, fulvic acids, amino acids, vitamins, natural plant hormones, etc.

Gibberellin contains a wide range of plant hormones. The most important component is a gibberellic acid that contributes to the active growth of plants.

Etamon is a growth stimulator for plants, a biological plant hormone product of the new generation for stimulating the formation of roots. It can be used for growing plants on open ground and in a greenhouse or under a cover. It can be used for treating seeds and vegetating plants. Primarily, the product stimulates the growth of roots, providing easy-to-digest forms of nitrogen and potassium for bioplasts.

Each variant of the experiment involved 100 seeds and was repeated four times. All work was carried out according to a state standard (GOST 13056.6-97). Trees and shrub seeds. The methods for germination ability determination. The pine and spruce seeds were soaked in products for 24 hours. The experiment involved seeds that were stored for a long time and which sowing quality was decreased. In the case of long-lasting or improper storing the intensity of growth processes decreases and the action of a stimulator becomes more evident [13].

The aim of this research is to study the influence of new fertilizing products on vigor and germinating ability of Scots pine and common spruce seeds.

\section{Results and discussion}

Tree and shrub seeds have high physiological activity during development and maturation. Their tissues contain a huge amount of mobile carbohydrates and nitrogen compounds. The germination of seeds starts with their swelling accompanied by splitting and oxidation of fats. Fats are used for the synthesis of organic acids, sugars and amino acids that takes place with the participation of oxidizing and hydrolyzing enzymes [14]. During the research, the first count of Scots pine sprouts was done on the 9th of April. The effect of seeds soaking in fertilizing products was visible already on the 4th day, which is proved by the singlefactor analysis of variance with $\mathrm{LSD}_{05}=2.2$. The biggest number of sprouts was given by Emistim-R with the value of $99 \%$, while the percentage in control variant was at the level of $32 \%$ (table 1). The rest of the product also showed positive effectson sprouting which accounted between 77 and $87 \%$.

Table 1. The average data on Scots pine sprouts, items

\begin{tabular}{|c|c|c|c|}
\hline \multirow{2}{*}{$\begin{array}{c}\text { The variants of the } \\
\text { experiment }\end{array}$} & \multicolumn{3}{|c|}{ The day of counting } \\
\cline { 2 - 4 } & 09.04 .2018 & 11.04 .2018 & 19.04 .2018 \\
\hline Control & 32 & 63 & 84 \\
\hline Potassium humate & 77 & 94 & 96 \\
\hline Humate+7 & 87 & 98 & 99 \\
\hline Biohumus & 92 & 94 & 96 \\
\hline Agrostimul VE & 86 & 94 & 99 \\
\hline Emistim-R & 99 & 100 & 100 \\
\hline LSD05 & 2.2 & 4.24 & 4.0 \\
\hline
\end{tabular}

The vigor of seeds was estimated on the 7th day of the experiment (11th of April).

There is a positive influence of fertilizers in all variants $(\mathrm{LSD} 05=4.24)$. The least number of sprouts $(63 \%)$ was in the case of control. In other cases, involving the fertilizing products the vigor was 94-100\%. The vigor increased, on average, between 31 and $37 \%$ in comparison with control variant (fig. 1, fig. 2).

On the 15th day, the control showed a relatively low germinating ability of Scots pine seeds equal to $84 \%$. In other cases, involving the fertilizing products the germinating ability of Scots pine was $96-100 \%$. The biggest germinating ability of seeds was showing with such products as "Emistim-R" (100\%), "Humate+7" (99\%) and "Agrostimul VE" (99\%), which is higher than control by $16 \%$ on average.

The number of empty seeds was determined on the 15th day according to national standards. The biggest amount of empty (10\%) and moldy (6\%) seeds was found in control variant.

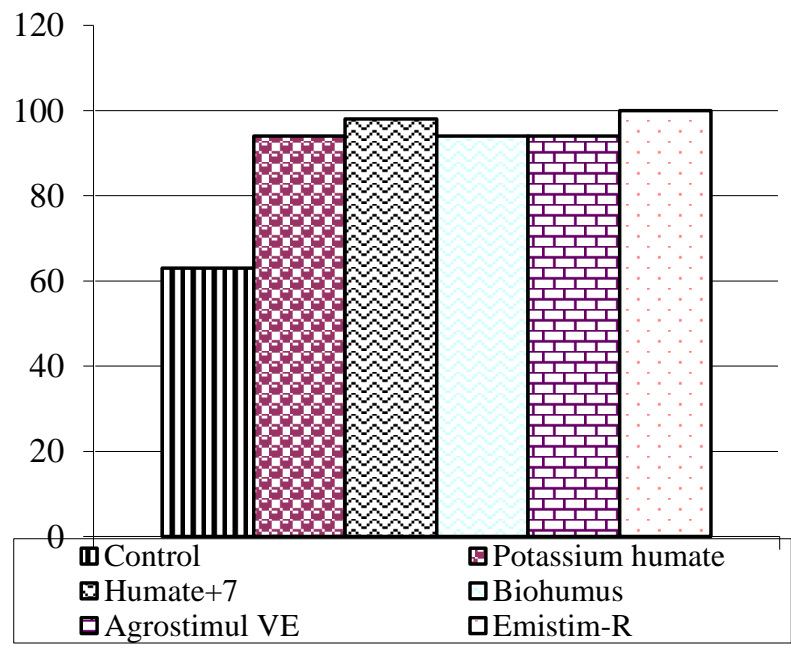

Fig. 1. The vigor of Scots pine seeds on the 7th day. 


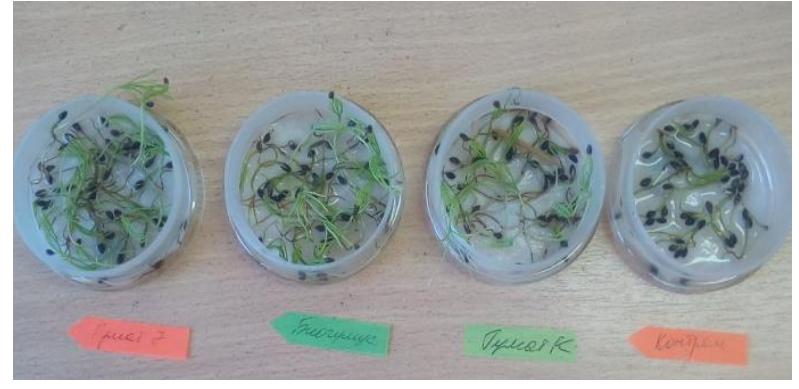

Fig. 2. The samples of Scots pine sprouts on 11.04.2018. From left to right: 1 . Humate+7; 2. Biohumus; 3 . Humate; 4 . Control

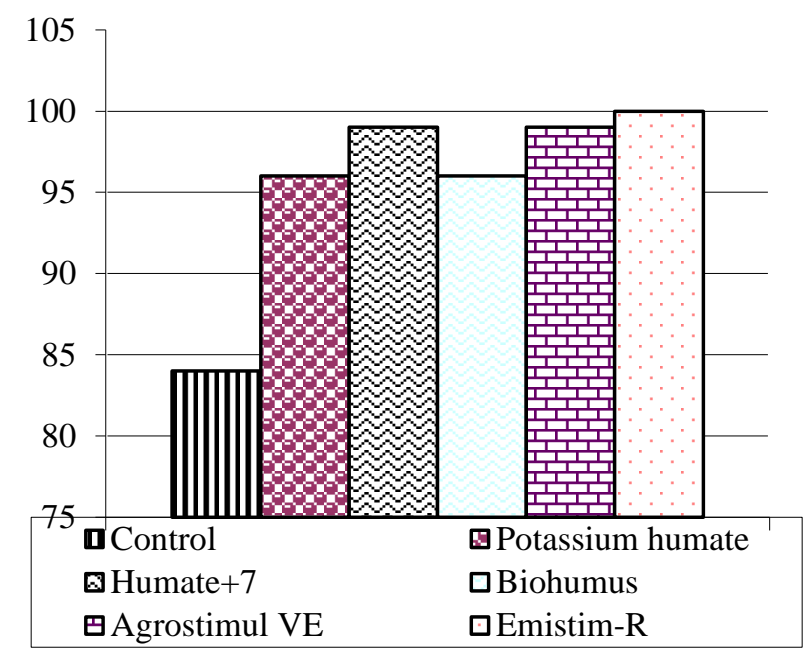

Fig. 3. The germinating ability of pine seeds on the 15th day of sprouting.

The linear parameters including the length of roots and the upper part of germs were measured on the 15th day. (see table 2). The biggest value was in case of seed treatment with "Potassium humate" and "Emistim-R". It was equal to $9 \mathrm{~cm}$ which is bigger than control by $5 \mathrm{~cm}$. It is worth noting that germs of seeds soaked in products have a different color. They have dark green color which is especially visible when seeds are soaked in such products as "Biohumus" and "Emistem-R".

Table 2. The length of Scots pine germs

\begin{tabular}{|c|c|c|c|}
\hline Variants & $\mathrm{L}-$ total & $\mathrm{L}-$ roots & $\mathrm{L}$ - upper part \\
\hline Control & 4 & 1 & 3 \\
\hline $\begin{array}{c}\text { Humate+7 } \\
\text { iodium }\end{array}$ & 8 & 3 & 5 \\
\hline $\begin{array}{c}\text { Potassium } \\
\text { humate }\end{array}$ & 9 & 3 & 6 \\
\hline Biohumus & 8.5 & 3 & 6.5 \\
\hline $\begin{array}{c}\text { Agrostimul } \\
\text { VE }\end{array}$ & 8 & 3 & 5 \\
\hline Emistim-R & 9 & 4 & 5 \\
\hline LSD05 & 3.10 & 1.63 & 2.51 \\
\hline
\end{tabular}

In general, pine seeds have a lower reaction on stimulators in comparison with spruce seeds. On the other hand, the germination of spruce seeds is slower, and the effects are more visible [11]. The following products were used for spruce seeds sprouting: Humate+7, Potassium humate "Sufler", Biohumus, Gibberellin, Etamon. During the research, the first count of spruce sprouts was done on the 19th of May. The biggest number of sprouts was given by Humate+7 with the value of $16 \%$, while the percentage of sprouts in the control variant was at the level of $1 \%$ (table 3 ). The rest of the products showed a lesser effect: the number of sprouted seeds was 3-6\%.

The second count of sprouted seeds was done after 3 days on the 22nd of May. The biggest amount of sprouted seeds was in the case of Potassium humate (74 items) which surpasses the control variant by $16.0 \%$. Among all the products the least effective was "Etamon" (37.0\%). In this case, there is seed depression, as the quantity of sprouted seeds is lower than control by $21.0 \%$.

Table 3. The average data on common spruce sprouts, items

\begin{tabular}{|c|c|c|c|c|}
\hline The variants of the & \multicolumn{4}{|c|}{ The day of counting } \\
\cline { 2 - 5 } experiment & $\begin{array}{c}19.05 . \\
2019\end{array}$ & $\begin{array}{c}22.05 . \\
2019\end{array}$ & $\begin{array}{c}25.05 . \\
2019\end{array}$ & $\begin{array}{c}30.05 . \\
2019\end{array}$ \\
\hline Control & 1 & 58 & 61 & 63 \\
\hline Potassium humate & 3 & 74 & 77 & 80 \\
\hline Humate+7 & 16 & 58 & 68 & 70 \\
\hline Biohumus & 3 & 60 & 66 & 69 \\
\hline Gibberellin & 6 & 69 & 74 & 74 \\
\hline Etamon & 4 & 37 & 48 & 53 \\
\hline LSD05 & 1.48 & 0.28 & 0.40 & 1.68 \\
\hline
\end{tabular}

The vigor of seeds was estimated on the 10th day of the experiment (25th of May) The major part of applied products has prompted the germination on the initial stage which has led to an increase in the vigor. The biggest number of sprouts was in the cases of "Gibberellin" and "Potassium humate" - 74 and $77 \%$ respectively. The least number of sprouts was in the case of "Etamon" - $48 \%$ against $61 \%$ in control.

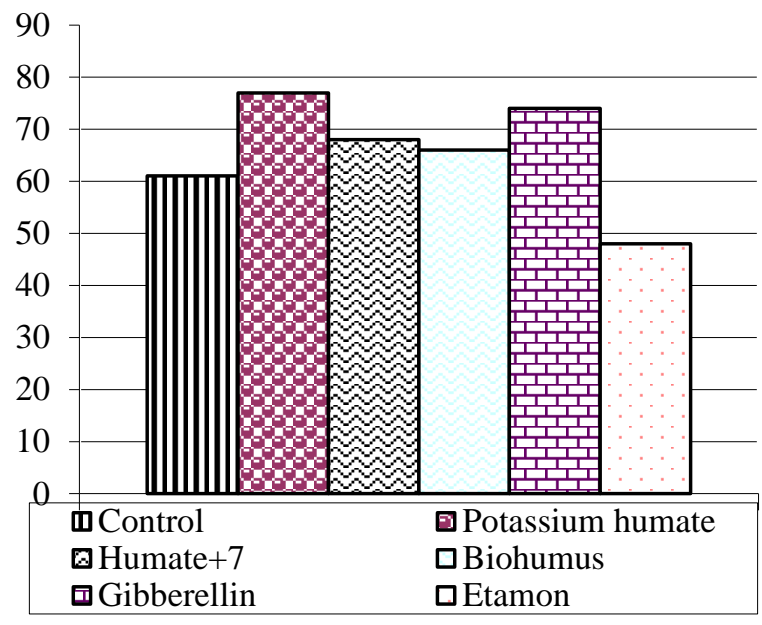

Fig. 4. The vigor of common spruce seeds on the 10th day.

The final results of sprouting the seeds of common spruce were obtained on the 30th of May. The biggest number of sprouts was in the cases of "Potassium humate" and "Gibberellin" - 74-80\% (LSD05 = 1.68) which is higher than control by $11-17 \%$. The same trend as in the case of seed vigor accounting was on the 15th day. All variants showed a positive influence of products, except "Etamon". In its case, the germination 
ability in the laboratory tests was $10.0 \%$ lower than in control.

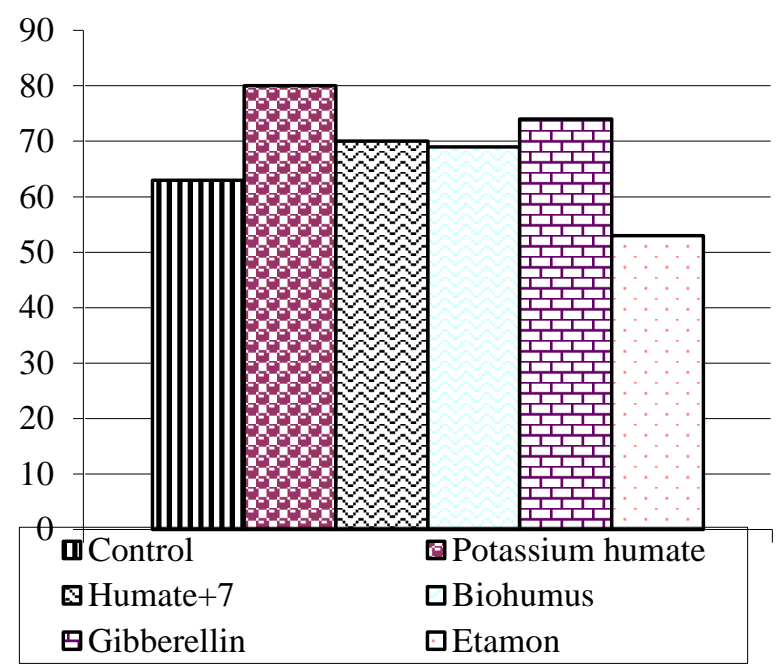

Fig. 3. The germinating ability of common spruce on the 15 th day of sprouting

The number of empty seeds was determined on the 15th day according to national standards. The biggest amount of empty seeds (32\%) was found in the control variant. The seeds with small amounts of mold and rottenness (1-3\%) were also accounted except the variant with "Etamon", where mold accounted for $8.0 \%$ and rottenness for $10 \%$.

The research also involved the measurement of common spruce sprouts length (table 3 ).

Table 4 shows that pre-sowing treatment positively increases the length of sprouts in comparison with untreated seeds. On the 7th day, the longest spruce sprouts were in the cases of "Gibberellin" and "Biohumus" with 1.7 and $1.5 \mathrm{~cm}$ respectively. On the 10th day, there was the same trend with the biggest values obtained in the same variants with 3.0 and $3.5 \mathrm{~cm}$ respectively. The same trend preserves in case of other variants using growth stimulators.

The linear parameters including the length of roots and the upper part of germs were measured separately on the 15th day. (see table 5) The biggest values were obtained in the cases of "Potassium humate" and "Humate+7" with 10.5 and 11.5 values respectively, which surpasses the control by 5.5 and $6.5 \mathrm{~cm}$ respectively.

The treatment by stimulators significantly influenced the development of a root system. The intensive root growth happens in the cases of "Gibberellin" and "Humate+7" - 4.4 and $5 \mathrm{~cm}$ corresponding to the variants of the experiment.

This is a big advantage when growing trees in forest nurseries because the growth and development of sprouts depend on the development of root systems.

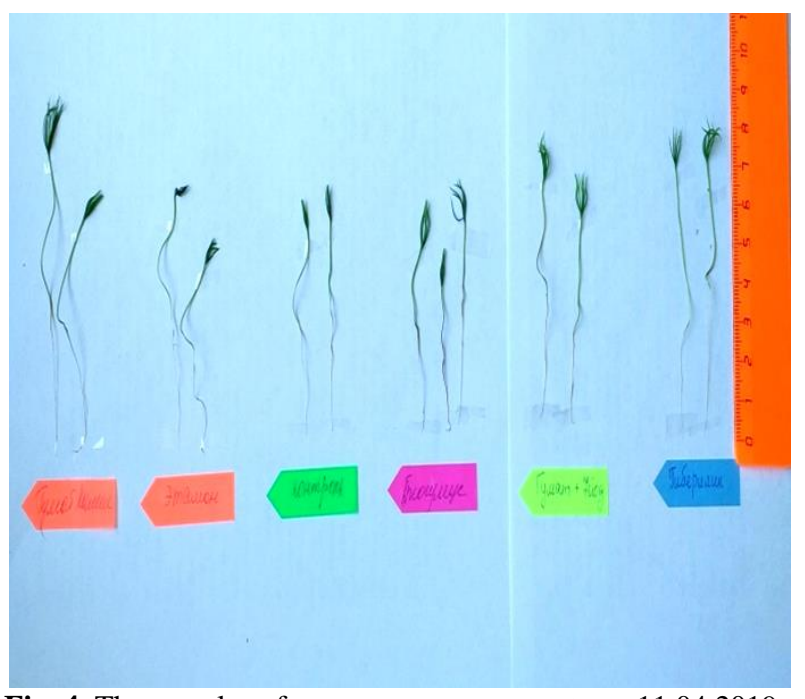

Fig. 4. The samples of common spruce sprouts on 11.04.2019. From left to right: 1 - Humate +7 ; 2 - Etamon; 3 -Control; 4 Biohumus; 5-Potassium humate; 6 - Gibberellin

Table 4. The average values of sprout length according to variants, $\mathrm{cm}$

\begin{tabular}{|l|c|c|c|}
\hline \multirow{2}{*}{$\begin{array}{c}\text { The variants of the } \\
\text { experiment }\end{array}$} & \multicolumn{3}{|c|}{ The day of counting } \\
\cline { 2 - 4 } & 19.05 .2019 & 22.05 .2019 & 25.05 .2019 \\
\hline Control & - & 0.9 & 1.9 \\
\hline Potassium humate & - & 1 & 2.2 \\
\hline Humate+7 & - & 1.3 & 2.8 \\
\hline Biohumus & - & 1.5 & 3 \\
\hline Gibberellin. & - & 1.7 & 3.5 \\
\hline Etamon & - & 1.1 & 1.9 \\
\hline LSD05 & & 0.28 & 0.50 \\
\hline
\end{tabular}

Table 5. The length of common spruce sprouts, $\mathrm{cm}$

\begin{tabular}{|l|c|c|c|}
\hline \multicolumn{1}{|c|}{ Variants } & $\mathrm{L}-$ total & $\mathrm{L}-$ roots & $\mathrm{L}-$ upper part \\
\hline Control & 5.5 & 3 & 2.8 \\
\hline Humate+7 iodium & 11.5 & 5 & 6.5 \\
\hline Potassium humate & 10.5 & 3.5 & 6.7 \\
\hline Biohumus & 6.5 & 3.3 & 3.5 \\
\hline Gibberellin & 7.3 & 4.4 & 3.5 \\
\hline Etamon & 9.2 & 4 & 5 \\
\hline LSD05 & 1.77 & 0.74 & 0.62 \\
\hline
\end{tabular}

\section{Conclusion}

The laboratory experiments on the pre-sowing treatment of conifer seeds showed that:

- soaking of seeds in fertilizing products leads to the increase in vigor, on average, between 31 and $37.0 \%$ for Scots pine and between 5 and $13.0 \%$ for common spruce;

- germinating ability of Scots pine and common spruce seeds increases, on average, by $16.0 \%$ and $17.0 \%$ correspondingly.

The pre-sowing treatment of seeds with fertilizing products has a high potential. However, to fix the results it is necessary to conduct field experiments in nurseries and greenhouses of the Republic of Tatarstan. 


\section{References}

1. M.G. Murtazin, S.G. Murtazina, I.A. Gaysin, H.G. Musin, Using JUSS product in forest nurseries Agrochemical bulletin 5, 25-27 (2009)

2. N.M. Vedernikov, G.A. Morozov, A.A. Nazirov, The influence of microwave treatment of pine and spruce seeds on their sowing qualities and resistance of sprouts to diseases in forest nurseries in Forests, forest sector and ecology of the Republic of Tatarstan: article collection 1, 38-44 (Kazan, 2005) 15

3. V.V. Nosnikov, A.P.Volkovich, V.A. Yarmolovich, Efficiency of presowing treatment of pine and spruce seeds with emistim-c drug Proc. of BSTU, Forestry 150-153 (2014)

4. R.S. Khamitov, Soil Germination Stimulation of Siberian Cedar Seeds by "Gumat+7" Agent The Bull. of Higher Educat. Institut., Forestry J. 6, 127-128 (2006)

5. Yu.I. Dobritskaya, E.G. Zhuravleva, L.P. Orlova, M.G. Shirinskaya, Zinc, copper, cobalt, molybdenum in some soils of the European part of the USSR, Microelements in some soils of the USSR (Nauka, Moscow, 1964)

6. T.M. Evstoratieva, Yu.L. Zherebin, A.F. Pozharitskiy, M.V. Reshetnik, O.A. Sirik, Microelements accompanied by bioactive ligands as growth stimulators for plants, Microelements in the exchange of substances and productivity of plants 88-89 (Naukova dumka, Kiev, 1984)
7. T.V. Khurshkaynen, E.M. Andreeva, S.K. Stetsenko, G.G. Terekhov, A.V. Kuchin, Influence of biopreparation Verva and VervaSpruce on the Scots pine seedlings growth Chemistry of plant raw mater. 1, 295-300 (2019)

8. N.P. Chernobrovkina, E.V. Rabonen, S.A. Igotti, The availability of mineral nutrient elements for conifers in terms of Karelian forest nurseries in Northern Europe in XXI century: nature, culture, and economy 237-239 (Karelian Research Centre Russian Academy of Sciences, Petrozavodsk, 2006)

9. V.S. Pobedov, Fertilizers in forestry (All-USSR Institute of Scientific Information on Agriculture, Moscow, 1969)

10. A.I. Novoseltseva, ed. The guidebook on forestry seed collection and storage (Forest industry, Moscow, 1978)

11. O.I. Yakhin, A.A. Lubyanov, I.A. Yakhin, P.H. Brown, Biostimulants implant science: a global perspective Frontiers in Plant Sci. 7 (2017)

12. O.I. Yakhin, A.A. Lubyanov, I.A. Yakhin, Modern ideas about biostimulators Agrochemistry 7, 85-90 (2014)

13. GOST 13056.6-97. Trees and shrub seeds. The methods for germination ability determination, Introduction. 01/07/1998 (The publishing office for standards, Minsk, 1998)

14. A.R. Safina, Effectiveness of different norms of ammonium nitrate application in cultivating seedlings spruce in Predkama zone of the Republic of Tatarstan Vestnik of Kazan. State Agrarian. Univer. 7, 1(23), 151-155 (2012) 